\title{
Propostas e possibilidades acerca de um cinema em grid no Brasil
}

Alfredo Luiz Suppia e Cícero Inácio da Silva

\section{Resumo:}

Este artigo pretende discutir a proposta de um sistema nacional, público e gratuito de difusão/circulação de conteúdo audiovisual em formato digital, fruto de discussões no âmbito do eixo Memória do I Seminário Internacional Fórum de Cultura Digital Brasileira, de 18 a 21 de novembro de 2009, em São Paulo. A idéia é que qualquer cidadão brasileiro tenha acesso gratuito e remoto a conteúdo audiovisual digital em alta definição (720p, 1080p, 1080i e/ou 2K), originário de arquivos e cinematecas dos mais diversos pontos do país. Tal projeto, um grid nacional de cinema e audiovisual, parte de experiências e projetos nacionais e internacionais como o CineGrid (http://www.cinegrid.org/), a exibição intercontinental de cinema 4K por ocasião do FILE 10 (Festival Internacional de Linguagem Eletrônica), de 28 de julho a 30 de agosto de 2009, em São Paulo, a Rede da Memória Virtual Brasileira (http://bndigital.bn.br/) e o Ponto Cine (http://pontocine.blogspot.com/).

\section{Palavras Chave:}

Cinema, tecnologia, redes, tecnocultura.

\begin{abstract}
:
This paper aims to discuss the idea of a free national digital audiovisual network. This proposal partially stems from a debate on Brazilian audiovisual heritage and memory, during the I International Seminar organized by the Brazilian Digital Culture Forum, November, 18-21, in São Paulo, Brasil. We stand for a network in which any Brazilian citizen can have free and mobile access to high definition (720p, 1080p, $1080 \mathrm{i}$ e/ou 2K) digital audiovisual content, provided by networked archives, collections, schools, universities and other cultural/educational institutions, located all over the country. This project, a national cinegrid, is inspired by other national and international, both governmental or non-governmental initiatives such as CineGrid (http://www.cinegrid.org/), the International Festival of Electronic Language (FILE: http://www.file.org.br/), The Brazilian Virtual Memory Network (Rede da Memória Virtual Brasileira: http://bndigital.bn.br/) or Ponto Cine (http://pontocine.blogspot.com/).
\end{abstract}

\section{Keywords:}

Cinema, technology, networks, technoculture.

Problemas se repetem na história.

Segundo Paulo Emílio Salles Gomes (1996: 9), "o que impedia o desenvolvimento do cinema no Rio, para não falar no resto do território ainda mais arcaico, era a insuficiência de energia elétrica". 113 anos depois, o cinema (ou audiovisual) brasileiro pode enfrentar obstáculo similar, devido ao atraso em matéria de banda larga.

O problema do abastecimento de energia elétrica no Brasil ainda não está completamente sanado. Por 
outro lado, um novo problema se apresenta. Atualmente, eletricidade apenas não é suficiente para o desenvolvimento de uma nação. É preciso conexão para tráfego de informações em rede. E tráfego rápido de informações, em grande quantidade. Portanto, além da necessidade de uma rede elétrica fail safe, é fundamental a implantação de uma rede de banda larga 100\% eficiente e confiável no Brasil.

Sensível a essa questão, o governo Lula recebeu proposta para um Plano Nacional de Banda Larga no dia 24 de novembro de 2009. Atualmente, cerca de $94 \%$ dos brasileiros não têm acesso a redes de banda larga. Essa grande maioria da população não pode assistir a vídeos no YouTube, fazer uso da web 2.0, adquirir softwares livres ou ter acesso a ciência, cultura, arte e tecnologia de última geração. Segundo pesquisa do Banco Mundial (BIRD), cada aumento de $10 \%$ em alcance de banda larga equivale a um crescimento de 1,3\% do PIB de um país. Nesse sentido, o Plano Nacional de Banda Larga encomendado pelo governo visa universalizar o serviço de internet rápida no país, por meio de uma política pública que, entre outros aspectos, incentive a participação do setor privado, em especial pequenas e micro-empresas, na ampliação da rede nacional de banda larga.

A Finlândia, cuja rede em banda larga serve $80 \%$ da população, a uma velocidade média de $22 \mathrm{Mbps}$, aprovou lei que defende conexão de $1 \mathrm{Mbps}$ como "direito fundamental" do cidadão a partir de junho de 2010. Itália também tem projeto de universalização de conexão em banda larga previsto para 2010 e o governo espanhol já anunciou que começará uma série de reformas na legislação, visando tornar o acesso à internet rápida um direito de todos os cidadãos a partir de $1^{\circ}$ de janeiro de 2010 . Extremamente cara e restrita às regiões mais industrializadas, a rede atual de banda larga no Brasil não é exatamente "larga", uma vez que conexões de $1 \mathrm{Mbps}$ estão entre as mais custosas, enquanto países como EUA, Japão, Suécia e Finlândia oferecem redes muito mais velozes. Estados como Acre ou Amapá ainda operam com conexão discada, como no início dos anos 1990. A universalização da banda larga no Brasil também deve ser encarada como "direito fundamental", e será fundamental para a manutenção do desenvolvimento do país em áreas como Educação, Pesquisa e Desenvolvimento, Ciência, Tecnologia e Inovação.

Mas uma boa rede de banda larga não é tudo - é preciso saber o que fazer com ela. As possibilidades são muitas fora da esfera do entretenimento. Gostaríamos de propor aqui um sistema de difusão/compartilhamento/circulação dos arquivos audiovisuais preservados, suportada pela RNP (Rede Nacional de Ensino e Pesquisa) (1) e envolvendo cinematecas/arquivos audiovisuais, universidades públicas federais, estaduais e pontos de cultura, por meio das quais qualquer cidadão brasileiro possa ter acesso gratuito a conteúdo audiovisual digitalizado (filmes, vídeos, programas de TV e afins), de forma integral e irrestrita e em alta definição (1280×720 pixels: 720 p ou 1920×1080 pixels: 1080i/1080p), sem fins comerciais ou lucrativos e conforme legislação sobre direitos autorais. A infra-estrutura adequada para um projeto dessa natureza pode ser buscada na RNP2, rede de alto desempenho com capacidade máxima de tráfego de 155 Mbps. Nesse sistema, conteúdo em domínio público seria disponibilizado em rede de forma imediata, para download ou visionamento em plataformas/interfaces específicas, à medida em que sua digitalização fosse sendo completada. Tal rede de fluxos é fundamental para a efetiva preservação da memória audiovisual brasileira, atendendo a demandas sociais amplas e/ou específicas, dentre elas a difusão democrática do patrimônio cultural brasileiro, o ensino e a pesquisa de audiovisual. Um sistema como esse vai ao encontro de trechos do Caderno de Resultados da I Conferência Livre de Comunicação para a Cultura, no qual se propõe

Criar um sistema público de distribuição de conteúdos produzidos pelas redes de comunicação e cultura e garantir que a produção cultural financiada com dinheiro público seja exibida e distribuída de forma livre, licenciada através de licenças flexíveis e disponibilizada em acervos livres.

Em “Acervos digitais públicos: convergência entre comunicação e cultura" (2009), Rogério Lourenço 
comenta o trecho acima:

Isso significa que será possível um dia, conectar escolas, universidades, bibliotecas, museus e outras instituições numa Rede de Conteúdos Livres, de acesso à cultura, do Brasil e mundial. Embora hoje a internet seja uma primeira etapa, na qual já podemos ir até lugares diversos, uma parte imensa do acervo cultural brasileiro ainda pode ser incluída. Preservar é mais que guardar. $E$ saber. Nesse momento em que se prepara a discussão sobre o falso dilema entre ideologia e prática, entre tecnologia e tradição, estar ciente de que a resolução dessas questões passa pela memória é fundamental.

Uma rede de compartilhamento da memória audiovisual brasileira poderia se beneficiar também de tecnologias agregadoras, como uma interface de visualização/download específica, em que o usuário tenha acesso não só ao conteúdo audiovisual requerido, como também à fortuna crítica e literatura disponível em formato digital referente àquele conteúdo.

Ao que tudo indica a Cinemateca Brasileira, associada a outros centros e ao MinC, tem no horizonte de seu projeto de digitalização a disponibilização pública do conteúdo. Mas a forma dessa disponibilização deve ser discutida. Conteúdo parcial e/ou em baixa definição é praticamente ineficaz. Nossa proposta é tentar estabelecer uma rede $100 \%$ democrática e eficiente, inspirada em modelos internacionais (EUA, Reino Unido, França), mas aperfeiçoada em relação ao contexto brasileiro. Tal rede teria um impacto positivo inestimável no âmbito do ensino e da pesquisa em audiovisual.

Em resumo, os benefícios da implantação de um grid de cinema público e de alta performance no Brasil abrangem 4 eixos principais: 1) benefícios de ordem social: democratização do acesso ao patrimônio cultural brasileiro e da qualidade de ensino; trata-se de ferramenta fundamental para democratização do acesso à cultura, contribuindo significativamente para o aumento da qualidade do ensino de audiovisual e de disciplinas afins em todas as regiões do país. 2) Econômica: barateamento de custos de difusão e distribuição de bens audiovisuais; o investimento necessário é muito inferior ao retorno social a médio e longo prazo, o sistema inibe a pirataria, divulga a cultura brasileira e pode gerar receita por meio de licenças a pessoas físicas ou, principalmente, jurídicas. 3) Ecológica: redução drástica na emissão de poluentes relacionada à produção e distribuição audiovisual; uma rede como essa reduziria drasticamente as "pegadas de carbono" (2) auferíveis na indústria e comércio do audiovisual contemporâneo. A abolição da película implica ausência de uso de derivados de petróleo, assim como ausência de emissões de CO2 por conta de fretes, por exemplo. Enfim, uma tecnologia mais limpa. E finalmente 4) benefícios de ordem estética: novos modelos de recepção/fruição do audiovisual. Modelos para o planejamento dessa rede podem ser buscados em iniciativas internacionais, nacionais e locais/regionais.

Com o surgimento de programas computacionais e sistemas de captura de imagem em super alta definição, é possível, na atualidade, obtermos imagens em movimento com resolução superior a 8 milhões de pixels por frame de cinema, o que significa dizer, na tradição do cinema analógico de 24 frames por segundo, que um segundo no formato digital 4K tem o equivalente a 192 milhões de pixels. Ou seja, as câmeras de cinema digital atuais, ainda restritas devido a dificuldade em se adquirir essa tecnologia - e compreendê-la -, podem capturar imagens que se compõe de outra materialidade, diversa da que tínhamos na película física.

Alguns grupos de trabalho e organizações ligadas a centros de pesquisa e inovação já estão criando protocolos para tentar compreender o que será esse cinema ligado em rede e quais as consequiências que podemos antecipar dessas novas configurações. Um dos mais proeminentes grupos na área de cinema em redes é o Cinegrid, uma organização de várias empresas e universidades que convergiu em um grupo avançado de pesquisa para a distribuição de imagens em movimento, por meio de uma nova categoria de 
sistemas computacionais em rede denominada grid. Empresas como Cisco, IBM, Intel, e universidades como Berkeley, UCSD, UCLA, Keio e, no Brasil, a Universidade Mackenzie, entre outras, são os fundadores dessa organização.

O que surgirá dessa imagem em super alta definição em termos de padrões culturais, sistemas e métodos, ainda está por ser definido e é um dos motivos pelos quais estamos interessados nesse tema.

Hoje é plenamente razoável pensar em transmitir conteúdo audiovisual para localidades distantes utilizando redes fotônicas de fibra óptica de super alta velocidade, ainda restritas às universidades e centro de pesquisa avançada ao redor do mundo. Redes como o GLIF (Global Lambda Integrated Facility), que já estão no Brasil através da Rede Nacional de Pesquisa (RNP) ou da rede Kyatera, da FAPESP, entre outras, já alcançam velocidades superiores a $10 \mathrm{Gbps}$ e podem transmitir informações com rapidez e eficiência, gerando uma nova plataforma para se pensar em protocolos de transmissão e recepção nos âmbitos da imagem fixa e em movimento. O consórcio CineGrid tem justamente como missão "construir uma comunidade interdisciplinar focada na pesquisa, desenvolvimento e na demonstração de ferramentas colaborativas em rede para permitir a produção, uso e troca de mídias digitais de super alta qualidade através de redes fotônicas" (http://www.cinegrid.org/).

Um dos primeiros experimentos na transmissão de imagens em super alta definição foi realizado no ano de 2007 quando da transmissão do Prêmio Kyoto, da cidade de Kyoto no Japão para a cidade de Estocolmo. A transmissão foi realizada através de redes de $10 \mathrm{Gbit}$ com mais de $21.000 \mathrm{~km}$ de extensão. Cada câmera no Japão capturava entre 3840 x 2160 pixels a 29.97 frames.

\section{Mapa do Global Lambda Integrated Facility (GLIF)}

No dia 30 de julho de 2009, um grupo liderado por pesquisadores da Universidade Mackenzie, de São Paulo, em conjunto com mais de 60 pesquisadores no Brasil e no mundo realizaram um feito inédito na história das redes e do cinema: transmitiram através de fibras ópticas (redes fotônicas) com velocidade em torno de $10 \mathrm{Gbps}$ um filme digital em super alta definição (4K) para dois países ao mesmo tempo. O Digital Media Center (DMC), da Universidade de Keio no Japão e o Calit2 da Universidade da Califórnia em San Diego, Estados Unidos, puderam assistir em tempo real ao filme "Enquanto a noite não chega", com direção de Beto Souza e Renato Falcão, com definição superior a 8.000.000 de pixels por frame. O formato $4 \mathrm{~K}$, como é conhecido esse novo processo de renderização de imagens cinematográficas, já foi aceito como a resolução mínima dos filmes que substituirão os padrões atuais pela DCI (Digital Cinema Initiatives), uma associação que congrega os 7 maiores estúdios de Hollywood.

A primeira transmissão de um filme em redes de super alta velocidade requer uma quantidade significativa de conexões e de roteadores, além de servidores de grande porte, para dar conta de projetar o filme e, além disso, de enviá-lo através de routers e distribuidores de informação para vários locais do mundo até chegar ao seu destino. Os servidores de renderização de imagens são potentes máquinas criadas especialmente para esse fim que podem ler 10, 20 terabytes de informação e projetá-las em tempo real. Um filme de 70 minutos em formato $4 \mathrm{~K}$ tem uma média de 4 a 8 terabytes (não comprimido).

As instalações das redes que fizeram a transmissão do primeiro experimento nessa área foram criadas para servir e interligar grandes centros de pesquisa ao redor do mundo. A experiência pioneira de utilizar essa infra-estrutura para a transmissão de cinema foi um marco na criação de novas formas de utilização dessas redes e também colocou o Brasil em um novo patamar em termos de distribuição, acesso e interligação de grandes bases de dados, que agora além de dados científicos e tecnológicos, passam a também distribuir cultura em forma de imagens em movimento, animações, performances teatrais, óperas e concertos. As redes utilizadas na transmissão são conhecidas como Kyatera, da FAPESP, ANSP e RNP, 
as quais abrangem universidades que possuem pesquisa na área de redes e fibras ópticas.

Atualmente existe um interesse crescente em interligar, além de centros de pesquisa avançados, espaços culturais como cinematecas, bibliotecas, filmotecas, teatros e salas de cinemas, entre outras instituições culturais, através de uma parceria entre a Rede Nacional de Ensino e Pesquisa (RNP) e o Ministério da Cultura. Uma iniciativa como essa seria inédita em termos de abrangência dessas novas redes e colocaria o Brasil como um potencial emissor de conteúdo cultural para os demais países conectados ao grid. Para se ter uma idéia, o Brasil é o único país listado no mapa do GLIF, ou seja, é o único que possui redes acima de $1 \mathrm{~Gb}$ na América Latina. Com essas conexões ativas, é possível que dentro de poucos anos o Brasil possa ser um centro de produção de filmes em larga escala. Com conexões rápidas, a edição de filmes pode ser realizada em tempo real de maneira compartilhada em vários países do mundo. A edição de áudio, a renderização da imagem, a aplicação de cores, enfim, todo o processo de edição pode ser feito em vários países ao mesmo tempo, com o diretor do filme no Brasil assistindo em tempo real ao que está sendo feito e podendo, ele mesmo, editar o filme em super alta definição.

Esquema de transmissão do filme "Enquanto a noite não chega" para a UCSD e Keio, de Beto Souza e Renato Falcão.

Como ainda existem algumas limitações em relação às taxas de transmissão e aos processos de codificação, encapsulamento e envio das imagens (pois ainda não existem comercialmente encoders e decoders capazes de realizar esse tipo de transmissão), muitos experimentos acontecem somente no âmbito dos centros de pesquisa ligados a redes como GLIF ou AMPATH.

Também é importante observar a existência de pesquisas que já apontam na possibilidade de uma transmissão $4 \mathrm{~K}$ bi-direcional, no sentido de permitir a interação com o público/audiência. Outro aspecto relevante no horizonte de possibilidades é a teleconferência utilizando super alta definição. As imagens geradas por sistema de vídeo conferência ou teleconferência em $4 \mathrm{~K}$ ampliam a dimensão da participação dos envolvidos, pois a capacidade de imersão é intensa e o delay mínimo em relação aos outros sistemas de transmissão via IP convencional. As redes que suportam conexões de alta capacidade e que enviam dados para outros países estão conectadas às redes Kyatera, da FAPESP, e à ANSP, entre outras no estado de São Paulo, e à RNP-Ipê, através da rede WHREN-LILA vinda de Miami de 2.5Gbit, que foi alterada para 10Gbit em julho de 2009. A infra-estrutura de conexão necessária para teleconferências ou distribuição de conteúdo audiovisual digital em super alta definição pode ser realizada através do sistema OptIPuter, uma rede ótica em escala global ligada através de dezenas de gigabits de conexão, utilizando o protocolo de Internet (IP) (www.optiputer.net). Cada ponto da rede seria interconectado e distribuído entre os grids já existentes, com os quais é possível obter acesso a diversos materiais cinematográficos postados em grids hospedados em grandes computadores ao redor do globo, como por exemplo no Supercomputer Center da UCSD (University of California at San Diego, EUA) ou no DMC do Japão.

No âmbito nacional, vale a pena destacar o projeto da Rede da Memória Virtual Brasileira, da Biblioteca Nacional Digital (http://bndigital.bn.br/redememoria/), que visa a digitalização e distribuição de bens culturais preservados. Segundo Muniz Sodré, Presidente da Fundação Biblioteca Nacional,

Rede da Memória Virtual Brasileira é um projeto tanto ambicioso quanto inédito. Primeiro, a saudável ambição de automatizar e disponibilizar no ciberespaço os acervos de todas as instituições nacionais que disponham de um patrimônio visual ou textual. Se a preservação física de um bem simbólico já assegura a permanência intergeracional de um traço valioso numa cultura consolidada, a memória digital acrescenta a promessa de ampliação do acesso a esse bem. É, por isto, um artefato poderoso de democratização do olhar e do conhecimento. (Sodré, 2009) 
Exemplo de iniciativa local ou regional desencadeada pela própria sociedade civil brasileira é o projeto Ponto Cine (http://pontocine.blogspot.com/), que emprega tecnologia Rain para exibição de filmes de forma acessível à população de baixa renda. Com o slogan "arroz, feião e cinema", a experiência do Ponto Cine já ganhou certificado Carbon Free e é ilustrativa dos benefícios de ordens social e ecológica provenientes de uma tecnologia como essa.

Por ocasião do I Seminário Internacional do Fórum da Cultura Digital Brasileira, de 18 a 21 de novembro de 2009, retomou-se presencialmente a discussão em torno da digitalização, preservação e circulação de acervos que já vinha ocorrendo há cerca de seis meses no âmbito do Fórum de Cultura Digital (www.culturadigital.br). O Seminário dividiu-se em 4 eixos temáticos: 1. Memória Digital (acervo, história e futuro); 2. Economia da Cultura Digital (compartilhamento, interesse público e mercado); 3. Infraestrutura para a Cultura Digital (infovia, acesso e inclusão); 4. Arte Digital (linguagem, democratização e remix); 5. Comunicação Digital (língua, mídia e convergência). Discussões importantes sobre digitalização, preservação e circulação de acervos ocorreram no âmbito do eixo Memória Digital. Segundo Rogério Lourenço, coordenador do eixo no Fórum de Cultura Digital,

A delimitação de algo denominado Memória Digital tem que explicar por que é importante que as legislações sobre arquivos, museus, bibliotecas, cinematecas, bem como acervos de rádio e televisão, nas quais os profissionais de diversas áreas se apegam na hora de dialogar com pessoas de campos diferentes, sejam pensadas como algo convergente, e não como um cerco.

A tecnologia digital é instrumento-chave no que diz respeito a políticas públicas de preservação de patrimônio cultural, no mundo inteiro. Em "Digital Cinema: A False Revolution”, John Belton observa que

Talvez a preocupação mais importante acerca da digitalização do cinema esteja em suas implicações para a preservação de filmes. No presente momento, safety film ou poliéster ainda são as mídias ideais para preservação de imagens em movimento e trilhas sonoras a longo prazo. A longevidade desse suporte é estimada em cerca de cem anos - mais se acondicionada em baixa temperatura. Informação digital tem sido estocada, na maioria das vezes, em fitas magnéticas ou discos - um formato que tem vida útil de cinco a dez anos e tempo estimado de obsolescência de apenas cinco anos. Os estúdios seriam loucos de usar formatos digitais para arquivamento de sua produção. Filme realizados digitalmente poderiam ser armazenados nesse formato, mas teriam de ser convertidos para novo formato a cada cinco anos. Dada a rápida obsolescência dos diversos formatos digitais passados, não está claro se essa informação digital pode ser recuperada no futuro. (2002, p. 114)

Preocupações como essa também ocuparam o centro das discussões no I Seminário Internacional Fórum da Cultura Digital Brasileira, especialmente no terreno dos debates em torno do softwares livres ou open source. Mas, ainda que a filosofia open source possa amenizar parte do problema levantado por Belton, é bastante provável que a maior contribuição da tecnologia digital não esteja no mero armazenamento de arquivos ou patrimônio cultural, mas sim em seu potencial de difusão e circulação efetiva, mais democrática e menos onerosa.

Belton reduz efetivamente a suposta "revolução" a uma questão de ordem econômica, capitaneada pela indústria de eletrônicos em busca de novos mercados e consumidores $(2002,101)$. Para contextualizar seu argumento, o autor entabula uma revisão histórica atenta da entrada da tecnologia digital no âmbito da arte e indústria cinematográficas. Belton observa que o digital penetra no cinema inicialmente por meio do som, no início dos anos noventa com tecnologias como Dolby Digital ou Dolby SRD (Batman Returns, 1992), e Digital Theatre Systems ou DTS (Jurassic Park, 1993). Do campo do som a tecnologia 
digital avança para o setor da captação, com câmeras digitais nos formatos mini-DV, DV, DV-Cam, Beta Digital, $2 \mathrm{~K}$ e $4 \mathrm{~K}$ oferecendo-se enquanto ferramentas de gravação para vídeo e cinema, em substituição a formatos analógicos obsoletos (VHS) ou mais caros (16mm, 35mm). "Ao final de 1999, com a celebração do falso-milênio, surge o advento de uma nova tecnologia, 'revolucionária' - a projeção digital." (Belton, 2002:103)

A partir de então algumas salas de cinema ao redor do mundo abrem-se para tecnologias digitais de projeção, como o caso do sistema Rain no Brasil. Até então observamos a tecnologia digital nas áreas de sonorização, captação de imagem e projeção, e em dois momentos da cadeia produtiva do audiovisual: produção e exibição. Para Belton, a tecnologia digital não promove uma verdadeira revolução no cinema porque não provoca uma verdadeira ruptura com modelos prévios de produção, e principalmente recepção. Segundo o autor, para a maioria dos espectadores leigos a tecnologia digital é um dado irrelevante, porque não evidente em termos de uma nova experiência de recepção (Belton, 2002: 108).

Belton pode estar certo em sua análise na medida em que não examina mais detidamente outro setor da cadeia audiovisual produtiva, inserido exatamente entre a finalização do bem audiovisual e sua exibição: a distribuição. Entendemos que a tecnologia digital pode proporcionar - e talvez já esteja proporcionando - experiências significativamente diferentes de recepção e, sobretudo, circulação de bens culturais audiovisuais. Se é possível falar numa "revolução" digital no campo da arte e indústria do cinema contemporâneo, esta deve ser buscada especialmente no escopo da distribuição digital de conteúdos em super-alta-definição e tempo real.

Por outro lado, Belton entrevê novidades promovidas pela tecnologia digital em termos de uma nova economia do audiovisual (Cf. 2002: 110-13). O autor preocupa-se eminentemente com a distribuição e exibição de bens audiovisuais comerciados, daí suas observações quanto à "pirataria".

Concordamos com Belton quando este chama a atenção para a fibra ótica enquanto canal seguro para distribuição de filmes. Mas, mais importante que a segurança talvez seja a eficiência desse canal. Percebe-se que a indústria do entretenimento já tomou consciência dessa revolução em termos de distribuição de conteúdo audiovisual e tem procurado ocupar seu espaço. Vide o caso da estréia de Titan A.E. nos EUA, citado por Belton (2002:113), e mesmo a reorganização do mercado de locação. Nos anos 1980, multiplicaram-se as videolocadoras de fitas VHS. Nos anos 1990, muitas dessas lojas foram "engolidas" pela concorrência de grandes redes de franchising em locação, nacionais ou estrangeiras (Blockbuster, 100\% Vídeo), e os acervos para aluguel começaram a migrar do analógico (VHS) para o digital (DVD). Essa situação se manteve no início dos anos 2000, mas perto do fim da primeira década do século XXI, o panorama muda novamente. A TV a cabo, digital via satélite e a internet banda larga concorreram para que a locação de DVDs tendesse à obsolescência. Atualmente, as grandes redes de videolocação enfrentam um cenário de encolhimento de mercado. A Blockbuster foi vendida para as Lojas Americanas e incorporada ao espaço físico da loja de departamentos. A rede $100 \%$ Vídeo, sediada em Campinas-SP, encolhe depois de um período de expansão nacional. Sair de casa para alugar um DVD já não faz muito sentido quando se tem a mão o pay-per-view ou sistemas de locação digital online, como o serviço oferecido pela livraria Saraiva (http://www.livrariasaraiva.com.br/download-filme-digital/), reprodução de um modelo de locação bem-sucedido nos EUA. É claro que a expansão desse mercado depende estreitamente das políticas públicas relativas à universalização de uma rede de banda larga verdadeira (e não a velocidades de apenas 1Mbps) no Brasil. E, a reboque ou não de iniciativas comerciais, é bem verdade que setores públicos como a educação e a cultura podem e devem fazer uso dessas novas tecnologias.

A necessidade de políticas públicas consistentes de digitalização, preservação e circulação de bens artísticos ou culturais naturalmente extrapola o escopo do audiovisual. Em seu artigo "Estado de Alerta", 
Suely Rolnik chama a atenção para uma "tomada de consciência coletiva de que o patrimônio artístico não pode ser tratado como matéria supérflua na agenda política" (2009: 8). Rolnik analisa a obra de Hélio Oiticica e comenta sobre o incêndio do acervo do artista para propor ações públicas como, por exemplo, "Pensar metodologias específicas de preservação e acesso para o tipo de práticas artísticas aqui focadas, as quais, com diferentes meios e poéticas, vêm se fazendo desde os anos 1960 (...)" (2009:10, grifo nosso), e finalmente "Fomentar a digitalização dos arquivos de arte como estratégia para impedir a perda dos documentos por deterioração ou por acidentes inesperados e facilitar sua acessibilidade." (2009:11, grifo nosso). Rolnik parece preocupada sobretudo com a preservação de acervos tridimensionais, algo que ainda desafia estratégias de digitalização. Suas preocupações são igualmente aplicáveis, no entanto, ao território do audiovisual. Destacamos, dentro das propostas, as menções a "metodologias específicas de preservação e acesso" e "facilitar sua acessibilidade", porque acesso e acessibilidade são palavras-chave no que pensamos em termos de um grid para o patrimônio audiovisual brasileiro.

A tecnologia digital tem sido ferramenta fundamental na recuperação e restauro de patrimônio audiovisual no Brasil e no exterior. Vide o caso de restaurações magníficas como as dos filmes Deus e o Diabo na Terra do Sol (1964) e Terra em Transe, de Glauber Rocha. Infelizmente, o resultado dessas restaurações, publicado em DVD, não está acessível ao grande público, em virtude do alto preço do disco ( $\mathrm{R}$ \$ 49,90 Deus e o Diabo na Terra do Sol, e R\$ 46,90 Terra em Transe, ambos DVD duplo). Mas, de acordo com Carlos Ebert,

Se no restauro dos acervos audiovisuais as soluções digitais vêm superando as fotoquímicas, o mesmo não pode ser dito quando o assunto é conservação. Em termos de durabilidade, universalidade e custo, o celulóide e o poliéster ainda são os suportes mais indicados para conservação das obras audiovisuais. Em recente estudo, a Academia de Artes e Ciências Cinematográficas de Hollywood (AMPAS) afirma que o atual padrão digital de $2 \mathrm{~K}$ por linha é inferior em qualidade à película de $35 \mathrm{~mm}$, e que o custo anual para arquivar um máster em $4 \mathrm{~K}$ de um filme em longa-metragem é de US\$104, contra pouco menos de US\$ 10 para a película. No fotoquímico, a técnica usada para o arquivamento de longo prazo dos filmes continua a ser a separação das cores primárias (RGB - vermelho, verde, azul) em internegativos preto e branco. No digital, um longa-metragem em $2 \mathrm{~K}$ resulta num arquivo de 2,5 terabytes, gravado numa mídia muito menos estável e que certamente estará obsoleta em alguns anos. O problema da rápida obsolescência dos formatos e das mídias digitais associado aos problemas de decaimento dos suportes magnéticos e ópticos ainda estão longe de serem superados e, a menos que novas descobertas e invenções surpreendentes nos domínios da informática quântica e das memórias orgânicas surjam, a prevalência da conservação em suporte foto-químico deverá permanecer ainda por alguns anos. Rick Utley, vice-presidente do serviço de preservação da Pro-Tek Media Preservation Services, resume a posição da comunidade dos conservadores de obras audiovisuais ao afirmar que "a tecnologia digital é maravilhosa e tem um tremendo potencial, mas no momento devemos assegurar o futuro e ter a certeza de que ele seja impresso em película cinematográfica". (Ebert, 2009: 24)

No entanto, vale a pena observar a velocidade das mudanças em matéria de tecnologia para digitalização e armazenamento. Por exemplo, recentemente a empresa Zaxel lançou no mercado sistema de digitalização que trabalha com arquivos $4 \mathrm{~K}$ ultracomprimidos, com custo anual de arquivamento da ordem de US\$ 5,50 (http://www.zaxel.com/pressroom/06-04-09.html). No experimento com a transmissão intercontinental em 4K no FILE 2009, a compressão do arquivo 4K de 70 minutos ocupou $120 \mathrm{~Gb}$. Um hard-drive externo de 2Tb custa cerca de US\$ 70.00 em média, e permite armazenamento de quase 15 filmes em $4 \mathrm{~K}$ com duração de 70 minutos cada um. Se observarmos que ainda não temos definida uma forma padrão para armazenamento de dados para audiovisual, ou seja, não sabemos se arquivaremos conteúdo em $2 \mathrm{~K}, 4 \mathrm{~K}, 8 \mathrm{~K}$ ou $200 \mathrm{~K}$, é preciso pensar no fato de que é possível comprimir 
imagens em formato TIFF (extensão de imagens de alta definição) e visualizá-las diretamente nesse formato frame a frame. Isso ainda não seria possível nos sistemas existentes, pois $200 \mathrm{~K} /$ frame x 30 frames por segundo gerariam imagens de tamanho descomunal para os computadores contemporâneos. Por outro lado, com o que se conhece da trajetória da imagem digital, se armazenarmos imagens em super alta definição, como uma sequiência de TIFFs com $200 \mathrm{~K}$ cada um, poderemos posteriormente reduzi-las facilmente para formatos que sejam executáveis pelos servidores existentes, como os de $4 \mathrm{~K}$ ou $8 \mathrm{~K}$, até chegarmos, talvez um dia, à definição de visualização de 200K. Dessa forma, o que interessa é analisar de que maneira ainda estamos presos às definições estáveis dos objetos, tais como filmes, películas e outros, tal como na discussão entre livro impresso e livro digital. Afinal, sempre que se quer encerrar o debate ou não tentar pensar sobre os problemas e questões existentes, resume-se tudo a um fato simplificador: o livro de papel pode ser lido sem a ajuda de nenhum aparato físico, assim como a película pode ser vista com uma simples fonte de luz. As questões que ficam suspensas quando partimos desses argumentos tornam a discussão reduzida e muitas vezes ingênua. O que realmente nos interessa agora é experimentar formatos e propor questões que busquem compor novas interpretações sobre como entendemos as imagens e como poderemos, algum dia, pensá-las de forma mais livre com respeito às suas relações objetuais e técnicas, assim como foi o argumento de Gutenberg ao inventar a prensa móvel, resistindo aos críticos que condenavam a invenção por não possuir uma estabilidade técnica que fosse mais avançada e segura do que as litografias existentes até então (Roger Chartier, 1999).

De toda maneira, até que toda a produção cinematográfica tenha migrado para o suporte digital - algo bastante provável num futuro não muito distante -, o cenário atual revela que grandes contribuições da tecnologia digital são oferecidas nos campos da recuperação/restauro e difusão/circulação. Dessa forma, não faz sentido digitalizar acervo audiovisual algum se não se tem por propósito a divulgação e circulação de filmes e vídeos, de maneira ágil, integral e com máxima qualidade disponível. Digitalizar para guardar melhor é um contra-senso. Digitalizar para conceder o usufruto de bens culturais a portadores de passwords, uma arbitrariedade pós-industrial. Nossa proposta de um grid de cinema para a memória audiovisual brasileira prevê, se - e somente se - necessário, num primeiro momento, um consórcio de instituições públicas detentoras da infra-estrutura, plataformas e softwares adequados, por meio das quais qualquer cidadão brasileiro poderia ter acesso ao conteúdo disponibilizado integral e gratuitamente no grid. Esse consórcio poderia reunir as universidades federais do país, beneficiárias da RNP2, bem como museus, bibliotecas e cinematecas. Nesse panorama, ainda que o grid seja razoavelmente "fechado" - por motivos operacionais -, qualquer cidadão poderia acessá-lo a partir de pontos especiais disponibilizados nas instituições consorciadas - por exemplo, uma universidade federal em sua cidade. $\mathrm{O}$ acesso residencial não é descartado e, na verdade, a idéia é que o sistema se alastre. Conexões com outros sistemas (grids) similares ao redor do mundo seriam conseqüência natural. Lembramos: digitalização só faz sentido para facilitar e difundir o acesso. A disponibilização total e irrestrita de conteúdos audiovisuais livre de implicações da ordem dos direitos autorais trará benefícios inestimáveis para a cidadania e melhoria do ensino, pesquisa e difusão cultural no país. Muito mais "alfabetização audiovisual", formal e assistida, muito mais memória e circulação de conhecimento.

Problemas se repetem na história. Mas é possível antevê-los e solucioná-los antes que se tornem definitivos. 


\section{Bibliografia:}

AGÊNCIA ELETRÔNICA. "A RNP e a história da internet brasileira”, 01.03.2002, disponível em http://www.agenciaeletronica.net/

ALMEIDA, Jane de. 4K: imagens de quatro quilates, in Perissinotto, P. \& Barreto, R., FILE 2008000 000, São Paulo: IMESP, 2008.

BELTON, John. “Digital Cinema: A False Revolution”. October, Vol. 100, Obsolescence. (Spring, 2002), pp. 98-114.

CADERNO DE RESULTADOS DA I CONFERÊNCIA LIVRE DE COMUNICAÇÃO PARA A CULTURA. $1^{a}$ Conferência Livre de Comunicação para a Cultura 2009/2010 - Recife (PE), disponível em http://www.cultura.gov.br/site/wp-content/uploads/2009/11/cadernoderesultados_iclcc.pdf, último acesso dezembro 2009.

CHARTIER, Roger. A Aventura do Livro: Do leitor ao navegador. São Paulo: UNESP/IMESP, 1999.

CHEN Han et al., "Data distribution strategies for high-resolution displays", Computers \& Graphics 25 (5) (2001) 811-818.

CRUZ-NEIRA, C., SANDIN, D., DEFANTI, T., KENYON, R., HART, J., "The Cave: audio visual experience automatic virtual environment", Communications of the ACM (1992), Junho.

DEFANTI T.A. et al. "The OptIPortal, a scalable visualization, storage, and computing interface device for the OptiPuter", in The International Journal of Future Generation Computer Systems Grid Computing: theory, methodos \& applications, vol. 25, issue 2, Feb. 2009, pp. 114.

DIAS, Tatiana de Mello. “94\% dos brasileiros não têm banda larga”, disponível em http://www.estadao.com.br/tecnologia/link/not_tec3147,0.shtm\#

EBERT, Carlos. “Cinema para sempre?”. Programadora Brasil, n. 3, setembro 2009.

GOMES, Paulo Emílio Salles. Cinema: trajetória no subdesenvolvimento. São Paulo: Paz e Terra, 1996.

LEIGH, J., et al., "The global lambda visualization facility: an international ultra-high definition widearea visualization collaboratory", Future Generation Computer Systems 22 (2006).

LOURENÇO, Rogério. “Acervos digitais públicos: convergência entre comunicação e cultura” (2009), disponível em www.culturadigital.br, último acesso novembro 2009.

MANOVICH, Lev. The language of new media. Cambridge: MIT Press, 2001.

Paulo: IMESP, 2008.

ROLNIK, Suely. “Estado de Alerta”. Arte!Brasileiros...2! São Paulo: Brasileiros Editora, 2009.

SANDIN, Daniel J. et al. The varrier autosterioscopic virtual reality display, ACM Transactions on Graphics, in: Proceedings of ACM Siggraph 2005, Los Angeles, CA, 31 de julho a 4 de agosto de 2005, 
vol. 24, no. 3, pp. 894-903.

SERRANO, Filipe. "Espanha vai tornar a banda larga um direito público", disponível em http://ow.ly/DwcX

SHIRAI, D. et al. "Real time switching and streaming transmission of uncompressed 4K motion pictures", in: The International Journal of Future Generation Computer Systems Grid Computing: theory, methodos \& applications, vol. 25, issue 2, Feb. 2009, pp. 192-193.

SODRÉ, Muniz. Apresentação da Rede da Memória Virtual Brasileira, disponível em http://bndigital.bn.br/redememoria/apresentacao.html, último acesso em novembro 2009.

\section{Notas:}

Este artigo foi produzido no âmbito do projeto de pesquisa "Cinema, Ciência e Tecnologia" e do grupo de pesquisa Laboratório de Estudos de Ficção Científica Audiovisual (LEFCAV), Universidade Federal de Juiz de Fora.

(1) A Rede Nacional de Ensino e Pesquisa (RNP) é uma organização de interesse público cuja principal missão é operar uma rede acadêmica de alcance nacional. Ela interliga hoje todos os 27 estados brasileiros, através de um backbone de alto desempenho: o RNP2.

(2) As "pegadas de carbono" medem quanto dióxido de carbono $(\mathrm{CO} 2)$ cada indivíduo produz em sua vida diária. O conceito e sua fórmula podem ser aplicados a determinadas atividades ou cadeias produtivas, com adaptações.

\section{Mini Currículo :}

Alfredo Luiz Suppia é professor de Cinema do Bacharelado Interdisciplinar em Artes e Design no Instituto de Artes e Design e no Mestrado em Comunicação da Faculdade de Comunicação Social da UFJF.

Cícero Inácio da Silva é professor do Bacharelado Interdisciplinar em Artes e Design no Instituto de Artes e Design e no Mestrado em Comunicação da Faculdade de Comunicação Social da UFJF. Pesquisador na área de tecnologias digitais, mídias e coordenador do Grupo de Software Studies no Brasil, além de pesquisador associado ao Center for Research in Computing and the Arts (CRCA) na Universidade da Califórnia, San Diego (UCSD). 